\title{
TIERRA, AUTONOMÍA Y ANCESTRALIDAD, UNA TRIADA DE PODER AL INTERIOR DE LA JURISDICCIÓN ESPECIAL INDÍGENA EN COLOMBIA*
}

\author{
Jacqueline Blanco Blanco**
}

\author{
Fecha de recibido: 11 de octubre de 2011 \\ Fecha de aprobación: 1 de diciembre de 2011 \\ Artículo resultado de Investigación
}

\begin{abstract}
Resumen
La Jurisdicción Especial Indígena es el más importante de todos los derechos conquistados por los indígenas colombianos en la Constitución Política de 1991, dado que ésta comienza siendo un marco territorial, al interior del cual se reconoce la práctica autónoma de gobierno, desempeño cultural, y administración fiscal y jurídica. Ciertamente el artículo $7^{\circ}$ constitucional reconoce la diversidad cultural del pueblo colombiano, pero no establece la existencia de un sistema paritario, por el contrario, los 18 artículos considerados como "especiales" en razón a su pertinencia para la preservación de las comunidades indígenas, deben guardar absoluta correspondencia con la Constitución que si bien reconoce, protege y preserva la alteridad, lo hace a partir de unos parámetros legítimos que delimitan los niveles de autonomía, para terminar haciendo efectiva una condición de dependencia tanto a la sociedad mayoritaria como al propio Estado. La JEI se sustenta en el carácter original y natural de sus residentes, esto es, la protección a alguna forma de ancestralidad que aún perviva, lo que termina siendo una condición que dificulta el intercambio, la co-relación directa, especialmente en materia de participación y beneficios, no sólo para con la sociedad sino también para con el Estado.
\end{abstract}

\section{Palabras clave}

Autonomía, ancestralidad, resguardo, jurisdicción especial indígena, justicia especial indígena.

* Este artículo es el resultado de una ponencia presentada en el "IV Congreso de Derecho y Sociedad: una mirada latinoamericana", realizado entre el 25 y el 27 de agosto de 2011 en la Universidad de Manizales, en el marco conmemorativo de los veinte años de la Constitución de 1991. Es una síntesis actualizada de las diversas investigaciones que se han adelantado al interior de la línea "Historia del Derecho en Colombia" sobre derechos civiles y políticos de las minorías étnicas nacionales, la línea forma parte del grupo "Derecho Público", categoría B - COLCIENCIAS 2010, de la Facultad de Derecho de la Universidad Militar Nueva Granada.

* Licenciada en Ciencias Sociales de la Universidad Libre, Especialista en Teoría del Derecho y Teoría Jurídica de la misma Universidad, Magister en Historia de la Universidad Industrial de Santander, doctoranda en Sociología Jurídica e Instituciones Políticas de la Universidad Externado de Colombia, con estudios en Pensamiento Indígena de la Universidad Nacional de Colombia. Autora de: "Colombia Multicultural, historia del derecho a la inclusión" (2005), "La jurisdicción especial indígena, más allá del mandato constitucional" (2008), "Historia y administración del Estado colombiano" (2010), coautora del profesor Oscar Mejía Quintana en "Democracia y filosofía de la historia en América Latina" (2005), y del "Diccionario histórico judicial de México" (2010), además de varios artículos publicados en revistas científicas especializadas. Miembro Vocal por Colombia del Instituto Latinoamericano de Historia del Derecho ILAHD y miembro fundador del Instituto Colombiano de Historia del Derecho. Correo electrónico: jacqueline.blanco@unimilitar.edu.co. 


\title{
LAND, ANCESTRALITY AND AUTONOMY, A TRIAD OF POWER TO THE INTERIOR OF INDIGENOUS JURISDICCION SPECIAL IN COLOMBIA
}

\begin{abstract}
The Special Indigenous Jurisdiction is the most important of all the rights previously acquired by indigenous Colombians in the 1991 Constitution, since it starts out as a territorial framework, within which recognizes the autonomous practice of government, cultural life, and management fiscal and legal. Certainly the Article 7th Constitutional recognizes the cultural diversity of the Colombian people, but not for the existence of joint, on the contrary, the 18 items considered as "special" because of their relevance to the preservation of indigenous communities must be consistent absolute correspondence with the Constitution while recognizing, protecting and preserving the otherness, it does from legitimate parameters that define the levels of autonomy, finally, enforcing a condition of dependency both mainstream society and the state itself. The JEI is based on the original and natural character of its residents, that is, some form of protection that still survive ancestral, which ends up being a condition that hinders the exchange, co-direct, especially in terms of participation and benefits, not only to society but also to the state.
\end{abstract}

\section{Keywords}

Autonomy, ancestry, indigenous reserve, special indigenous jurisdiction, special indigenous justice

\section{TERRA, AUTONOMIA E ANCESTRALIDADE, UMA TRIADA DE PODER AO INTERIOR DA JURISDICCION ESPECIAL INDIGENA EM COLÔMBIA}

\begin{abstract}
Resumo
A Jurisdição Especial Indígena é o mais importante de todos os direitos conquistados pelos indígenas colombianos na Constituição de 1991, uma vez que começa como um quadro territorial, no qual reconhece a prática autônoma de governo, o desempenho cultural e gestão fiscal e legal. Certamente o artigo 7 Constituição reconhece a diversidade cultural do povo colombiano, mas não para a existência de seu articulação, ao contrário, os 18 itens considerados como "especial" devido a sua relevância para a preservação das comunidades indígenas devem ser consistentes correspondência absoluta com a Constituição reconhecendo ao mesmo tempo, protegendo e preservando a alteridade, ele faz a partir de parâmetros que definem o legítimo níveis de autonomia, finalmente, impor uma condição de dependência tanto a sociedade mainstream e do próprio Estado. O JEI é baseado no personagem original e natural de seus moradores, ou seja, alguma forma de proteção que ainda sobrevivem ancestralidade, o que acaba sendo uma condição que dificulta a troca, co-direta, especialmente em termos de participação e benefícios, não só para a sociedade, mas também para o Estado.
\end{abstract}

\section{Palavras-chave}

Autonomia, ascendência, reserva indígena, jurisdição indígena especiais, justiça indígena especiais 


\section{INTRODUCCIÓN}

El estudio de las comunidades indígenas colombianas, como parte de las denominadas minorías étnicas nacionales, ha sido motivo permanente de reflexión al interior de los proyectos que han alimentado la línea de "Historia del Derecho en Colombia", correspondiente al ejercicio investigativo y académico que propicia la Universidad Militar Nueva Granada a través de su Facultad de Derecho; dicha preocupación ha sido abordada tanto en indígenas como en afrodescendientes en un amplio marco histórico que parte de los tiempos hispánicos y se prolonga hasta la actualidad, con particular atención a todo lo relativo a los derechos civiles y políticos, que no siempre les han asistido.

"Tierra, autonomía y ancestralidad", son tres conceptos alrededor de los cuales gira este artículo por considerarlos una "triada de poder", tal como se describe en el título. Desde la conquista española, la tierra ha sido un elemento importantísimo por el cual han luchado los indígenas, no sólo en Colombia, sino a lo largo del continente americano, por tratarse de la "pacha mama" o "madre naturaleza" a la cual se hallan fuertemente arraigados, porque constituye el eje central de su mundo. La tierra como lugar de asentamiento, constituye también el escenario natural de una anhelada autonomía, claramente definida por el Estado en cuanto a su naturaleza y función jurídica con apego a la Constitución, tal condición de "auto" es reconocida en razón al grado de ancestralidad perviviente, lo que termina siendo una condición culturalmente básica, a veces, culturalmente peligrosa, en ocasiones.

Este artículo es parte de una ponencia presentada en la Universidad de Manizales en el "IV Congreso de Derecho y Sociedad: una mirada latinoamericana", realizado entre el 25 y el 27 de agosto de 2011, el tema de la exposición se debió al pretender una mirada retrospectiva de los Derechos Especiales en Colombia como parte de la conmemoración de los primeros 20 años de la Carta Política de 1991, por lo tanto es una síntesis de numerosos trabajos que sobre el tema se han desarrollado en diferentes proyectos de la línea "Historia del Derecho", partiendo del problema de Derechos Especiales en riesgo de desaparecer, al igual que las comunidades y bajo la hipótesis de que no sólo el conflicto, sino también el Estado, la sociedad en general y las mismas comunidades, están aportando elementos para que este alarmante estado de cosas prospere.

El objeto de conocimiento parte de la importancia de la tierra como eje de protección y desarrollo para las comunidades indígenas, a la vez, señala que si bien el derecho a la tierra es fundamental, no debe asumirse desde un lugar de apartamiento sino como un sitio de protección, que no los desvincule necesariamente de su realidad y de un contexto que día a día evoluciona y se perfecciona con mayor rapidez y al cual están necesariamente insertos, que de no ser así, los conminaría a una forma de exclusión con respecto al tiempo y a los avances del resto de la sociedad.

Entre los métodos de trabajo que se han seguido está el método histórico, que ha dado lugar a un recorrido legislativo entorno al derecho a la tierra en Colombia, muy propicio para la entrada a la temática, por cuanto ubica al lector en la importancia que ha tenido este elemento para las comunidades indígenas desde tiempo inmemoriales y las diversas formas de despojo que han enmascarado los intereses políticos de algunos gobiernos; luego, con la ayuda del método dialéctico se plantea un ejercicio de causa - efecto en cuanto al análisis conceptual de los términos "autonomía" y "tradición", lo que lleva a un debate acerca de la pertinencia de uno y otro y a la co-relación de los dos, siendo ambos parte importante de lo contenido en el 246 constitucional y que hace referencia a la JEI. Finalmente, el método lógico, como apoyo para la interpretación de las diversas leyes tratadas, vistas a través de contextos más amplios y con efectivos resultados en cuanto a la apreciación acerca del impacto social indígena y al impacto político que se les quiso otorgar en su momento. 


\section{EL DERECHO A LA TIERRA COMO EJE HISTÓRICO DE DESARROLLO PARA LAS COMUNIDADES INDÍGENAS}

Con la República, los indígenas recibieron un tratamiento socialmente distinto al que se les daba a los negros, es decir, que no fueron considerados esclavos en razón a sus condiciones particulares de etnia, lengua y costumbres; sin embargo, esta primera forma de reconocimiento a las diferencias de los naturales de América no duró mucho, los principios fundamentales del sistema liberal que se había implementado también les competieron y en atención al derecho a la igualdad los indígenas debieron abandonar su situación y tratamiento singular, de alguna manera privilegiado, mientras la nueva tendencia los involucraba en el tema de los derechos individuales, al interior de una sociedad que cada vez tendía hacia un mayor grado de homogeneidad. Esta novedad del liberalismo proponía que para hacer efectivo el derecho a la igualdad, el Estado debía suspender las mínimas consideraciones de que gozaban los indígenas frente al resto de la población; por ejemplo, la propiedad colectiva sobre la tierra, por cuanto esta forma de tenencia invocaba argumentos coloniales útiles en su momento para legitimar la existencia de los resguardos, estos últimos, representaban parte del viejo arquetipo traído de España y sobre el cual se había erigido victoriosamente tanto la República como la Democracia y el Liberalismo:

La igualdad ante la ley requería que los indígenas se volvieran "ciudadanos y propietarios; pero, [...] para vergüenza de la Nueva Granada, existen hoi, a los cuarenta y dos años de la Independencia, dentro de su propio territorio, rebaños de hombres con el nombre de comunidades de indígenas. (Sanders, 2007, P. 32).

La afirmación niega la vuelta a la anterior propuesta colonial que contribuyera a "resguardar" unas determinadas características que, lejos de ser entendidas desde la alteridad, constituían una amenaza a la propuesta asimilacionista que propendía por una sociedad predominantemente blanca, sinónimo de civilización.

El afán jurídico por superar la propiedad colectiva sobre la tierra, había empezado ya en la Independencia, con el Decreto de la Junta Suprema del 24 de septiembre de 1810, luego, cuando las Constituciones establecieron que el gobierno garantizaría a los ciudadanos la propiedad y la libertad individual ${ }^{1}$. Por el Decreto de 5 de julio de 1820 (Semper, 2006), Bolívar ordenó devolver las tierras de resguardo a los indígenas, pero con la Ley de 11 de octubre de 1821 se estableció el repartimiento de las tierras indígenas en "pleno dominio y propiedad", de acuerdo a los innovadores y recién inaugurados conceptos sobre propiedad privada y derechos individuales, el repartimiento se haría dependiendo de la extensión del terreno, del número de los individuos que conformaran la familia, y de si esta última tributaba o no (Morales, 1994).

En 1828, Bolívar retomó su preocupación por devolver los resguardos a los indígenas, por lo que expidió la Ley de 20 de mayo (Bushnell, 1994), e incluyó en ella la necesidad de repartir aquellas tierras que se encontraban ocupadas sin aprobación (Artículo $2^{\circ}$ ); además de ratificar la necesidad de distribuir la tierra a partir del número de personas que la integraran (Artículo $3^{\circ}$.), las tierras que sobraran del repartimiento podían ser arrendadas, previa aprobación de los jueces políticos(Artículo $4^{\circ}$ ); por la misma Ley fue aprobado el pago a los indígenas que se les contratara para desempeñar algún trabajo; ante el incumplimiento a esta disposición, debía condenarse a pagar el doble del valor establecido al agraviado (Artículo 12)".

La Ley de 6 de marzo de 1832 dispuso que los resguardos fuesen distribuidos en doce porciones para su repartimiento: una destinada a la escuela y al sostenimiento de la misma, otra cuya función era cubrir los gastos de medición y repartición que había ordenado el gobierno,

CONSTITUCIÓN DE CUNDINAMARCA DE 1811, art. 16. En: www.cervantesvirtual.com 
y que finalmente no había sido consultado con los indígenas, ni mucho menos habían contado con su participación, de esta forma el Estado fue cediendo su responsabilidad social a los mismos indígenas, tras la idea de la autonomía sobre las propiedades. Las diez restantes, seguirían las siguientes disposiciones: 1 . Se formarán tantas partes cuanto sea el número de familias de indígenas de que conste la misma comunidad, para adjudicar una a cada una; y se reputan como familia distinta, aquellos individuos que no estén comprendidos en otra. 2. Estas partes serán proporcionalmente mayores o menores, en lo posible, cuanto sea mayor o menor el número de individuos de la familia a que se adjudique cada parte" (Mejía, s.f.). Esta Ley de 6 de marzo fue importante porque prohibió la venta de las parcelas hasta un período de diez años, exceptuando los casos en los cuales los indígenas debieran trasladar su lugar de ubicación. En 1843 fue expedida la Ley del 23 de junio, cuyo principal aporte fue prolongar la prohibición de la venta de los territorios por diez años más, es decir, por veinte años. Por Ley del 22 de junio de 1850 "se autorizó a las Cámaras de Provincia para "arreglar la medida, repartimiento, adjudicación y libre enajenación de los Resguardos de Indígenas".

Para 1866, un grupo de indígenas de la comunidad de los Quillacingas de Pasto, los Mocondinos, anunciaron con franca seguridad que el fin de los naturales (como cultura, como etnia y como raza) estaba muy próximo, en razón a las condiciones de miseria económica a que los conducía la política de exterminio de los resguardos: "de poco tiempo nuestros terrenos formarán la hacienda de un rico o un poblado de gentes de raza blanca (y que ellos tendrían que volverse) miserables jornaleros" ${ }^{2}$. La más próxima vocación para la cual los gobernantes habían preparado a los indígenas, desde las decisiones jurídicas, se veía llegar, el sometimiento a un nuevo "patrón" que se comprometía a cancelar el trabajo realizado y exclusivamente contratado.

2 Pequeño Cabildo Indígena de Mocondino al Presidente del Departamento Soberano del Cauca. Pasto, febrero 18 de 1866, ACC, AM, p. 94, leg. 54. En: IBID., p.36.
El dilema acerca del restablecimiento de los resguardos como equivalente al derecho a la tierra, que permitía el desarrollo de la cultura indígena en Colombia, fue finalmente legitimado mediante la Ley 89 de 1890, esta Ley participó de los objetivos sociales trazados por el gobierno de Rafael Núñez, y contenidos en la Constitución de 1886, a pesar que -contrariamente- la Ley guardara un fin "civilizador" de los indígenas a manos de la iglesia católica, al definir a los indígenas que no se sometieran a la autoridad eclesiástica y a los planes misionales como "salvajes" (Artículo 10), miembros de "sociedades incipientes". Además de volver al sistema territorial del resguardo, esta Ley 89 fue muy importante porque le mantuvo el carácter de no enajenable y no embargable (Artículo $7^{\circ}$ Numeral $7^{\circ}$ ), sumado a esto concedió una cierta autonomía a los Cabildos para el manejo de lo político, lo económico y lo judicial:

Artículo $3^{\circ}$. En todos los lugares en que se encuentre establecida una parcialidad de indígenas habrá un pequeño Cabildo nombrado por éstos conforme á sus costumbres.

Artículo $4^{\circ}$. En todo lo relativo al Gobierno económico de las parcialidades, tienen los pequeños Cabildos todas las facultades que les hayan transmitido sus usos y estatutos particulares, con tal que no se opongan a lo que previenen las leyes, ni violen las garantías de que disfrutan los miembros de la parcialidad en su calidad de ciudadanos.

Artículo. $5^{\mathbf{0}}$. Las faltas que cometieron los indígenas contra la moral, serán castigadas por el Gobernador del Cabildo respectivo con penas correccionales que no excedan de uno o dos días de arresto.

A finales del siglo S. XIX se conoció de una nueva e importante alternativa en la producción agrícola nacional: primero la quina y luego el caucho, ambos cultivos provocaron el desplazamiento de colonos e inversionistas extranjeros interesados en la explotación de estos dos recursos 
naturales. En lo que tocaba a la explotación, industrialización y comercialización del caucho, los interesados se fueron ubicando al sur del territorio nacional, específicamente entre los ríos Caquetá y Putumayo. De este episodio se recuerda con mucho dolor la llegada de la Casa Arana en el año de 1903, propiedad del comerciante peruano Julio Cesar Arana, cuyo principal interés estaba en la producción de látex. La Casa Arana, como empresaria del caucho en Colombia, daría cuenta de uno de los sucesos más graves relacionados con la explotación de los indígenas de los territorios del sur del país, a más de medio siglo de haberse puesto fin a la esclavitud. La memoria más clara que sobre este incidente social se dispone se encuentra en la novela "La Vorágine", escrita por don José Eustasio Rivera en el año 1922.

El personal de trabajadores está compuesto, en su mayor parte, de indígenas y enganchados, quienes, según las leyes de la región, no pueden cambiar de dueño antes de dos años. Cada individuo tiene una cuenta en la que se le cargan las baratijas que le avanzan, las herramientas, los alimentos, y se le abona el caucho a un precio irrisorio que el amo señala. Jamás cauchero alguno sabe cuánto le cuesta lo que recibe ni cuanto le abonan por lo que entrega, pues la mira del empresario está en guardar el modo de ser siempre acreedor. Esta nueva especie de esclavitud vence la vida de los hombres y es transmisible a sus herederos. (Rivera, 2005, p. 223).

La esclavitud prohibida ocho décadas atrás y ratificada a lo largo de siete constituciones (entre 1821 y 1886), fue desconocida en absoluto. Si bien con la Constitución de 1886 los indígenas habían perdido el derecho político a elegir, continuaban participando del cuerpo social, que para entonces conformaba la nación y con ello, siendo sujetos de protección y atención por parte del gobierno y del Estado, sin embargo, en su momento acusaron desconocimiento -más bien desgobierno y falta de control- frente a lo que sucedía en las selvas del Putumayo y Amazonas. Los indígenas fueron víctimas de los atropellos físicos, psicológicos, laborales, sociales más escandalosos que se hubieran registrado a lo largo del siglo XIX, incluso, aquello que había sido aprobado mediante la Ley 11 de octubre de 1821 sobre la cancelación que debía hacerse al trabajo que se les encargara, fue vilmente desconocido, hasta el núcleo familiar fue destruido, todo esto ante los ojos indiferentes de un Estado que no registró a su favor la más mínima intervención:

El señor Arana ha formado una compañía que es dueña de los cauchales de La Chorrera y los de El Encanto. iHay que trabajar, hay que ser sumisos, hay que obedecer! Ya nada queda en la pulpería para regalaros. Los que no hayan podido recoger ropa, tengan paciencia. Los que están pidiendo mujeres, sepan que en las próximas lanchas vendrán cuarenta, oídlo bien, cuarenta, para repartirlas de tiempo en tiempo entre los trabajadores que se distingan. Además saldrá pronto una expedición a someter a las tribus "andoques" y lleva encargo de recoger "guarichas" donde haya. Ahora, prestadme toda atención: cualquier indio que tenga mujer o hija debe presentarla en este establecimiento para saber qué se hace con ella (p. 230).

La primera Ley de tierras expedida en el siglo XX fue la Ley 30 de 1903, que atendía lo relativo a las formas de propiedad sobre el subsuelo patrio; esta preocupación transformó el sentido original de la Ley 89 y buscó expiar el camino a los latifundistas nacionales, al confirmar "la legalidad de la venta de los resguardos efectuados en subasta pública y los derechos de los rematadores (mediante la Ley 55 de 1905, expedida durante el gobierno del general Rafael Reyes). La ley 104 de 1919 ratificó la división de los resguardos y dispuso severos castigos expresados en despojo de la tierra 
para aquellos indígenas que se opusieron a la división. Posiblemente fue una reacción contra la rebelión de los terrajeros del Cauca -dirigida por Manuel Quintín Lame- quienes entre 1914 y 1918 habían disputado el poder de la élite payanesa en las montañas del Cauca" (Pineda, s.f.); finalmente, la Ley 19 de 1927, estableció una vez más, el derecho a parcelar los resguardos, lo mismo que a ser objeto mercantil (Castro 2007). Sin mayores pretensiones, el afán por legitimar la acción comercial sobre las tierras de los resguardos, y por definir la propiedad sobre el subsuelo nacional y las riquezas en él contenidas guardaba relación con el auge del petróleo, que marcaría la ruta económica de Colombia, a lo largo de todo el nuevo siglo y todo el proceso jurídico se haría aprovechando la imprecisión que había manejado la Ley 89 en cuanto a si el carácter de los indígenas, con respecto a la tierra, era de posesión como propietarios, o de usufructo, como lo menciona el artículo 38. La definición de estas dos condiciones, fue dirimida por la Corte Suprema de Justicia que estableció la propiedad plena de los indígenas sobre los resguardos:

En el análisis de la Corte se definió muy claramente que los terrenos cedidos a los municipios nunca tuvieron el carácter de baldíos. Además de lo anterior, la Corte indicó que los indígenas no eran usufructuarios de los terrenos de los resguardos, sino plenos propietarios, $y$ que por tal razón los terrenos vacantes que habían sido transmitidos a los municipios incluían el subsuelo. (Mayorga, 1994)

La Ley 200 de 1936, célebre obra del Presidente Alfonso López Pumarejo y tal vez la más importante de Ley Agraria de la primera mitad del siglo XX, no respondió a las expectativas de los indígenas, en cuanto al restablecimiento de su posesión y propiedad territorial, por el contrario, fue utilizada por los colonos para hacer pasar las tierras de resguardo, bajo la calificación de "baldías" y al aplicarles los 10 años que indicaba la Ley, como tiempo para la expropiación, lograron obtener la titulación legal a su favor, por encima del conflicto social que cada vez se hacía más agudo entre las comunidades indígenas (Herreño, 2004).

En medio de tanta incoordinación entre el Estado y la Ley agraria, se hizo relevante una figura que encarnaba el liderazgo de estas comunidades en su lucha por la reivindicación de uno de los derechos de mayor significación social: el derecho a la tierra. Manuel Quintín Lame Chantre, había logrado una reunión con los cabildos de las comunidades de Tolima, Huila, Tierradentro, Cauca y Valle, en 1914, con el fin de organizar una manifestación para el 14 de febrero de 1915, en la cual se hiciera manifiesta la propuesta de formar una "República Chiquita de indios", en la cual se pudiera ejercer la autonomía de los indígenas a favor de la conservación de su raza y su cultura; este plan le valió a Lame un período de nueve meses en prisión (Quintín, s.f.). Con el tiempo, esta no fue la única prisión que debió pagar Quintín Lame, pero bien valieron sus acciones, para lo que a futuro sería la propuesta política más importante y favorable para los indígenas nacionales, que sólo se vería reflejada en la Constitución Política de 1991, en este sentido, la historia debe concederle la autoría a Quintín Lame de lo que hoy se tiene como la participación de los indígenas en el Congreso de la República (art. 171), la autonomía en el manejo de su propia administración y la existencia de unos territorios definidos por el Estado para ejercer su propio gobierno (art. 246). En 1939, Quintín Lame escribió un Tratado ciertamente profético, en el cual describía la relación entre el indio y el blanco, y la desventaja del primero en su lucha por la autonomía:

"El presente libro servirá de horizonte en medio de la oscuridad para las generaciones indígenas que duermen en esos inmensos campos que tiene la naturaleza divina; pues el blanco es enemigo acérrimo del indígena que no golpea la puerta del engaño; que no quiere las promesas, que no le vende barato; lo mismo que el empleado público se une con el capitalista fundamentalista y el abogado para hacerle 
perder la finca al indígena, el semoviente, etc.". (Castro, 2007)

La ventana al mundo, que hizo público la denuncia de la situación que vivían los indígenas en Sur América, fue la "revolución mexicana" (1910 - 1920) liderada por Pancho Villa. A partir de entonces surgieron unos y otros movimientos a favor de la identidad latinoamericana, los que se iban logrando gracias a un ejercicio académico y social que se concentraba a partir de los primeros encuentros internacionales abordados por antropólogos y sociólogos que se fueron convirtiendo en los adalides del proceso indigenista suramericano. Por ejemplo, del I Congreso Indigenista Interamericano que promovió el presidente de México Lázaro Cárdenas se creó en Colombia, en 1941, el Instituto Indigenista Colombiano dirigido por Antonio García y Gregorio Hernández de Alba, su objetivo era la defensa del resguardo (Pineda, s.f.). Más adelante, el proceso se fue concretando y fortaleciendo gracias a los esfuerzos aportados por el Estado, que había venido entendiendo la necesidad de asumir también parte de este compromiso social, así fue como durante el Frente Nacional se creó la Oficina de Negocios Indígenas, que luego se llamó División de Asuntos Indígenas, y que dependía del entonces Ministerio de Gobierno; la misión educativa que adelantó esta dependencia, fue asignada a los miembros del Instituto Lingüístico de Verano, en 1962, en parte, por la necesidad de ampliar la actividad misionera que tiempo antes se había concentrado en manos de la Iglesia Católica, pero de la cual hubo muchas críticas, por cuanto terminó siendo una misión educativa con carácter aculturizante, que trajo confusión y división entre los naturales y su verdadero origen.

De acuerdo con la política de devolver los derechos territoriales a los indígenas, el Presidente Alberto Lleras Camargo expidió la Ley 135 de 1961 que respondía al cierto sentido proteccionista, relacionado con las tierras, al tenor de la Ley 89 , lo novedoso de esta disposición estuvo en la conformación de Reservas Indígenas ${ }^{3}$ en las selvas y sabanas. Bajo esta figura se crearon 158 unidades territoriales entre 1965 y 1986, sobre un área de 12 millones y medio de hectáreas, para 128 mil personas (Jimeno, 1992). También propuso la Ley, la ampliación y fortalecimiento de los territorios indígenas a través de la adquisición de nuevas tierras (Artículo 94), esto último se logró durante el gobierno del Presidente Virgilio Barco, con el Decreto 2001 de 1998, que hizo realidad lo propuesto en la Ley 135 a través de la compra y asignación de terrenos baldíos y mejoras del Fondo Nacional Agrario. Con el tiempo, la nueva reforma agraria y el gobierno, debieron ajustarse a las disposiciones logradas en el Convenio 107 de 1957 de la OIT, al cual se adhirió Colombia mediante la ley 31 de 1967, en este Convenio se estableció la defensa de ciertos grados de autonomía, y la constitución de reservas y resguardos indígenas.

\section{EL RECONOCIMIENTO SOCIAL, UNA ESTRATEGIA POLÍTICA}

La Constitución de 1853, o de la República de la Nueva Granada, puso fin a más de 30 años de deliberaciones republicanas, democráticas y liberales entorno a la calidad de ciudadanos a que debían acceder todos los habitantes del territorio, incluidos los negros y los indios. $\mathrm{El}$ art. $3^{\circ}$ de la Constitución estableció, por primera vez que: "son ciudadanos los varones granadinos que sean, o hayan sido casados, o que sean mayores de veintiún años", es decir, las viejas condiciones de posesión de bienes rurales o urbanos, de renta anual fija o de grado de alfabetismo, habían quedado atrás, una nueva puerta se habría para dos sectores históricamente segregados: los derechos políticos.

El censo poblacional del año 1843 había dicho que el $10 \%$ de la población granadina era

3 Es un globo de terreno baldío ocupado por una o varias comunidades indígenas que fue delimitado y legalmente asignado por el INCORA a aquellas para que ejerzan en él los derechos de uso y usufructo con exclusión de terceros. 
indígena, o sea, un número que se aproximaba a los 198.410, de un total de 1.955.264 habitantes (AAVV, 2000). La cifra, para nada despreciable, cobró importancia política, por lo que el sector llamó la atención de los dos partidos políticos legítimamente conformados hacía ya varios años, el liberal y el conservador.

De antigua data, existía un develado roce entre liberales e indígenas, se recuerda la insistente propuesta de reconocer a los indígenas como "sujetos de derechos individuales", lo que afectaba el tradicional manejo colectivo de la tierra y del desarrollo de su cultura, estas políticas se habían convertido en razones de antipatía de los segundos hacia los primeros, lo que en consecuencia los había llevado a refugiarse en sus benefactores de siempre: la Iglesia Católica, ésta última muy identificada con la causa, al sentirse víctima de la Ley de "Desamortización de bienes de manos muertas" que los había reducido a un mismo espacio físico, les había confiscado parte de sus bienes improductivos, y les había obligado a pagar impuestos. Con este precedente, era claro que el 10\% de la población del año 1843 a que se hace referencia, correspondía entonces a las filas del conservatismo.

En el año 1859, bajo la Presidencia del General Tomás Cipriano de Mosquera, fue expedida la Ley 90, cuyo objeto central era devolver los resguardos a sus verdaderos propietarios. Antes de seguir, es preciso anotar que el General Mosquera había militado inicialmente en las filas del conservatismo, gracias a las cuales había llegado a la Presencia en 1845, separándose de este sector en el año 1854 para adherirse al liberalismo, al lado de quienes empezó siendo gobernador del Estado del Cauca en 1858; en 1861 fue nuevamente Presidente tras derrocar a Mariano Ospina Rodríguez, por lo que le correspondió sancionar la Constitución de Río Negro en 1863, la más liberal en la historia política colombiana. Este último triunfo no fue del todo liberal, la Ley 90 de 1859 a favor de los indígenas, había logrado que estos personajes trasladaran su fuerza electoral del conservatismo al liberalismo (Sinisterra, s.f.). Así pues, el art. $3^{\circ}$ de la Constitución de 1853 fue llevado a un cierto pragmatismo democrático, que le sirvió al bipartidismo para asaltar su capacidad de elegir (de los indígenas), pero no de ser elegidos porque no les estaba permitido. Para fortalecer tanto la presencia política, como su llegada al poder, de hecho, la falta de representatividad para este sector hizo que las condiciones sociales se mantuvieran en marginamiento, la novedad que traía la constitución de la Nueva Granada no le reportó beneficios a los indígenas, pero sí al bipartidismo, que a partir de promesas incumplidas llegaron a manejar la voluntad electoral tanto de libertos como de naturales, aún en condiciones de indefensión y analfabetismo, es por eso, que en el mismo año de 1853, el gobernador de Quinchía manifestó al gobernador provincial, el abandono en que se hallaban, el desconocimiento de sus derechos y el mínimo respeto a su condición de ciudadanos: "no tenemos autoridad alguna ante quién reclamar o dirigir acción alguna, porque los funcionarios locales nos tratan como si fuéramos sus esclavos".

Este particular derecho político que insertó como novedad la Constitución de 1853 fue suspendido en la Constitución de 1886 en su art. 15: "Son ciudadanos los colombianos varones mayores de veintiún años que ejerzan profesión, arte u oficio, o tengan ocupación lícita u otro medio legítimo y conocido de subsistencia". Otra vez surgieron condiciones que restringieron el derecho político a elegir, contrario a afianzar el paso y a haber ampliado la posibilidad, a la de ser elegidos, la Ley 89 de 1890 consideró que los indígenas eran "menores de edad" en cuanto a su capacidad mental, y que aún requerían de las luces de la civilización para ser rescatados del estado de "salvajismo" en que según ella aún se encontraban. La iglesia de la mano con el bipartidismo, a finales

4 Del Gobernador de indígenas de Quinchaya al Gobernador Provincial. Popayán, abril 1 de 1853, AGC, AM, p. 55, leg. 85. Ver también Alcalde Mayor Indígena del Municipio de Obando a la Secretaría de Gobierno, Ipiales, marzo 4 de 1866, AGC. En: En: SANDERS, James. Pertenecer a la gran familia granadina. Lucha partidista y construcción de la identidad indígena y política en el Cauca, Colombia, 1849-1890. Ob. Cit., p.34. 
del siglo XIX y primera mitad del XX, llegaron a los indígenas para obtener un lucro particular que no necesariamente les involucraba como parte de sus agenda de gobierno, esta afirmación se hace con base en el testimonio ofrecido por Manuel Quintín Lame en una entrevista que otorgó al periodista Mario Ibero, en el año de 1824: "Hay muchas misiones que están contra los indígenas. Solamente se valen de nosotros cuando llegan las elecciones. A los indios que se resisten a votar por Cristo les dicen que si no lo hacen quedan excomulgados y que el diablo se los llevará para el infierno" (Ibero, s.f.).

\section{EL CONCEPTO DE AUTONOMÍA EN LA JURISDICCION ESPECIAL INDÍGENA}

La última Ley que marcó beneficios para las comunidades indígenas colombianas, antes de la Constitución de 1991 y anterior a las decisiones de la OIT en 1989, fue la Ley 89 de 1890, que pese a lo excluyente, trajo aportes significativos como la devolución de las tierras de los resguardos, el restablecimiento del derecho de autogestión, y la exención del servicio militar y del carácter de tributarios.

Colombia reconoció la Convención 169 de 1989 de la OIT sobre Pueblos Indígenas y Tribales en la Constitución Política de 1991, esta Convención había sido insertada al derecho nacional con la Ley 21 de 1991, igualmente, es expresada en el art. 7 de la C.P. que desarrolla el tema del reconocimiento y protección a la diversidad étnica y cultural.

Para el fortalecimiento del art. $7^{\circ}$ que se menciona, la misma Carta reconoció la existencia de comunidades indígenas, afrocolombianos, raizales y rom, como parte de la diversidad étnica y cultural en Colombia, y estableció a su favor una serie de derechos que contribuyen a su protección y preservación:

1. DERECHOS CULTURALES: Reconocimiento y protección por el Estado a la diversidad étnica y cultural (art. 7); reconocimiento de lenguas indígenas en sus territorios, al igual que la etnoeducación y la enseñanza bilingüe (art. 10, inciso 5 del art. 68); libertad de conciencia y cultos (art. 8 y 19); defensa del patrimonio cultural (art. 72); reconocimiento a justicia propia en sus jurisdicciones (art. 246); igualdad y dignidad de sus culturas como fundamento de la nacionalidad (art. 70).

2. DERECHOS TERRITORIALES: Reconocimiento de los resguardos como propiedad colectiva de la tierra con sus características de inalienable, imprescriptible e inembargable (art. 63); reconocimiento de los territorios indígenas como entidades territoriales de la nación y de su autonomía para darse su propio gobierno y conseguir su propio desarrollo (art. 286).

3. DERECHOS AMBIENTALES Y DE EXPLORACION DE RECURSOS NATURALES: Derecho a tener un ambiente sano (art. 79); a conservar los recursos naturales y a la garantía de desarrollo sostenible (art. 80), esto incluye la consulta previa para explorar los recursos en sus territorios,

4. DERECHOS POLITICOS Y SOCIALES: Derecho de los indígenas a ocupar dos curules en el Senado de la República (Art. 171); a poseer doble nacionalidad en el caso de los indígenas que habitan en zonas de frontera (art. 96, literal c)

5. DERECHOS ECONOMICOS: Asimilación de los resguardos a municipios para que participen de los ingresos corrientes de la nación (transferencias, art. 357).

En atención a los compromisos contraídos por la C.P. de 1991 para con los indígenas, el art. 392 , numeral 2 , establece que los resguardos son el eje del desarrollo cultural de estos pueblos, por lo tanto "son de propiedad colectiva y no enajenable"; este artículo se complementa con el art. 63 que establece la inembargabilidad e imprescriptibilidad de los mismos, pero, la Constitución deja sentada una posición, que 
ya antes se había tratado y que correspondió a una discusión ventajosa por parte del Estado en materia de tierra, por allá por los primeros años del siglo XX: la propiedad sobre el subsuelo, que según el art. 332 "El Estado es propietario del subsuelo y de los recursos naturales no renovables, sin perjuicio de los derechos adquiridos y perfeccionados con arreglo a las leyes pre existentes"

Para establecer claridad sobre la forma de proceder frente a la propiedad colectiva de los indígenas sobre las tierras de los resguardos y la propiedad del Estado sobre las riquezas del subsuelo y en atención al parágrafo del art. 330 de la $\mathrm{CP}$, referida a que: "la explotación de los recursos naturales en los territorios indígenas se hará sin desmedro de la integridad social, cultural y económica de las comunidades indígenas", la Corte Constitucional desarrolló el instrumento de "consulta previa" y lo dotó de la misma protección de que gozan los derechos fundamentales ${ }^{5}$, lo cual significa que es un deber consultar previamente a la Comunidades Indígenas por parte del Estado, cuando se pretendan adelantar proyectos $\mathrm{O}$ macroproyectos que de una u otra forma puedan alterar su "día a día" que consagra la $\mathrm{CP}$ en el art. 246, asegurándose, de paso, el cumplimiento del art. 7, referida a la protección de la diversidad étnica y cultural.

Con todo lo anterior, no es fácil entender por qué el litigio interpuesto por los U'wa y por los Embera cordobeses, no prosperó frente a la empresa OXY y frente al Estado colombiano respectivamente y cómo las riquezas naturales del subsuelo y las necesidades de un macroproyecto para la región, hicieron posible que a pesar de la protección legítima consagrada no sólo en la $\mathrm{CP}$, sino también mediante el Bloque de Constitucionalidad, parte de estos territorios de resguardo hubieran sido cedidos para los fines específicos de explotación de petróleo, y de construcción de la represa hidroeléctrica de Urrá. Finalmente prosperó el principio del "bien general", que también es consagrado

5 COLOMBIA. CORTE CONSTITUCIONAL. Sentencia T-625 de 1998. www.corteconstitucional.gov.co constitucionalmente, para verdadera satisfacción de todos o para la eterna incomprensión de pocos (Artículo 366, C.N.).

Acerca de la propiedad colectiva sobre los resguardos, la Corte Constitucional, en la sentencia T-380 de 1993, estableció que las Comunidades Indígenas en Colombia" son sujetos de Derechos Colectivos y no acumulación de sujetos de derecho individuales, para una mejor comprensión se trae el Decreto 2001 de 1998, que define en su art. 2 el concepto de Comunidad Indígena: "[...] el conjunto de familias de ascendencia amerindia que comparten sentimientos de identificación con su pasado aborigen y mantienen rasgos y valores propios de su cultura tradicional como formas de gobierno y control social internos que las distinguen de otras comunidades rurales", esto es, que la propiedad colectiva que reza la Constitución, le es correspondiente a las comunidades en razón de su significativo pasado étnico y racial y que el objeto principal de esta decisión está en la conservación cultural, a partir de una serie de garantías otorgadas por el Estado al interior de su marco territorial. Sobre la relación directa que existe entre la tierra y las Comunidades Indígenas, las Naciones Unidas señalan que no sólo ésta (la tierra) es el epicentro de su desarrollo cultural, sino también las razones de los grandes vejámenes e infamias de que han sido víctimas:

Las poblaciones indígenas o aborígenes son aquellas que estaban viviendo en sus tierras antes de que llegaran los colonizadores de otros lugares, los cuales al convertirse en el grupo dominante - mediante la conquista, la ocupación, la colonización o por otros medios - segregan o discriminan a los pobladores originarios. Cada vez que los pueblos vecinos dominadores han ampliado sus territorios o llegan colonizadores de tierras lejanas, las culturas y el sustento de los indígenas han estado en peligro. Estas amenazas han evolucionado a través de los años, sin embargo no han desaparecido por lo que las poblaciones autóctonas son 
consideradas como uno de los grupos más desfavorecidos en el mundo 6 .

Una vez identificado el concepto de Comunidades Indígenas, ¿̇por qué la importancia de establecer un carácter colectivo como forma de propiedad sobre la tierra? Para empezar, se presenta una definición sobre derechos colectivos elaborada el profesor Agustín Grijalva:

Son derechos humanos específicos de los cuales son titulares ciertos grupos humanos. Los derechos colectivos son parte de los derechos llamados de tercera generación cuyo reconocimiento internacional fue históricamente posterior a la de los derechos civiles y políticos (primera y segunda generación) y a la de derechos económicos, sociales y culturales (de tercera generación).

Algunos derechos de tercera generación son el derecho al desarrollo, a la paz, al patrimonio artístico y cultural, a un medio ambiente sano, los derechos de los pueblos indígenas y los de los consumidores. (Grijalva, s.f., p. 1)

En Colombia, los derechos colectivos se hallan consagrados en el título III, arts. 78, 79, 80, 81 y 82 , con específica referencia a los consumidores, a los residuos nucleares, desechos tóxicos, armas químicas, biológicas y nucleares, al manejo del espacio público, y a la conservación y cuidado del medio ambiente, y pese a no especificar el derecho colectivo que asiste a los indígenas, le ha correspondido a la Corte Constitucional ampliar y precisar este concepto, que es del todo operable.

Ahora bien, sobre el tema de la propiedad colectiva sobre la tierra, su importancia se debe al pleno desarrollo de la autonomía a que da lugar el resguardo, el art. 287 de la CP es el indicador más preciso: gobierno por autoridades propias, ejercicio de las competencias correspondientes,

6 Naciones Unidas - Centro de Información. En: www.cinu.org.mx administración de recursos y establecimiento de tributos necesarios para el cumplimiento de sus funciones, participación en las rentas nacionales. Y en los arts. 329 y 330, se halla la especificación del ejercicio de la autonomía: "De conformidad con la Constitución y las leyes, los territorios indígenas estarán gobernados por consejos y reglamentados según los usos y costumbres de sus comunidades y ejercerán las siguientes funciones:

1. Velar por la aplicación de las normas legales sobre uso del suelo y poblamiento de sus territorios.

2. Diseñar las políticas y planes y programas de desarrollo económico y social dentro de su territorio en armonía con el Plan Nacional de Desarrollo.

3. Promover las inversiones públicas en sus territorios y velar por la debida ejecución.

4. Percibir y distribuir sus recursos.

5. Velar por la preservación de los recursos naturales.

6. Coordinar los programas y proyectos promovidos por las diferentes comunidades en sus territorios.

7. Colaborar con el mantenimiento del orden público dentro de su territorio de acuerdo con las instrucciones y disposiciones del Gobierno Nacional.

8. Representar a los territorios ante el Gobierno Nacional y las demás entidades a las cuales se integren.

9. Las que les señale la Constitución y la Ley.

El ámbito territorial, se constituye entonces en el epicentro del desarrollo de la autonomía, en cuanto a su autodesarrollo cultural en lo referido a la lengua y dialectos, la religión y sus usos y costumbres, en cuanto a su autogestión 
administrativa y en cuanto a su auto administración política y jurídica, todo lo cual se halla contenido en el art. 246 de la CP, previa claridad acerca de la autonomía que el Estado le reconoce y concede a la Jurisdicción Especial Indígena, en tanto no puede superar ni contravenir los marcos constitucionales, como Ordenamiento Superior; esta última consideración se hace específica en la sentencia C-139 de 1996, donde la Corte estableció cuatro elementos centrales de la Jurisdicción Indígena: La posibilidad de que existan autoridades judiciales propias, la potestad de estas autoridades para establecer normas y procedimientos propios, la sujeción tanto de las autoridades como de las normas a la Constitución y la competencia del legislador para señalar las forma de coordinación, entre la jurisdicción indígena y el sistema nacional; así, la Corte ratifica la CP de 1991 como límite normativo de la autonomía administrativa indígena, entendiéndose como límite, una forma de no generar la independencia total de las Comunidades con respecto al Estado y acudiendo a Kymlicka (1996, p. 33), como una forma de "encuentro" legal entre dos culturas que requieren de igual protección y garantía, pero en diferentes condiciones de aplicabilidad.

Esta forma de "encuentro", como se le ha denominado en este artículo, se hace necesaria y resulta favorable en la medida que es el establecimiento de un diálogo frecuente con el mundo, aún cuando se precise guardar las distancias necesarias para evitar pasar de un lenguaje compartido a un lenguaje aprendido; en estas condiciones, el marco de referencia jurídico que la CP de 1991 le demarca a la Jurisdicción Especial Indígena colombiana, le abre la posibilidad de tomar lo mejor del otro en cada caso, eso implica que las comunidades no tengan ni deban alejarse y mantenerse resguardadas en la selva, apartadas de todo contacto con la sociedad mayoritaria, que bien les reporta beneficios como resultado de un largo trasegar en materia de desarrollo científico y tecnológico. Este es un debate ampliamente conocido y sustentado por quien escribe, ante la reticencia de muchos que consideran la conservación de la cultura original distanciada de una realidad que les corresponde a todos, por el contrario, es una consideración particular el hecho de sostener que este tipo de distanciamiento en pos de la preservación natural puede llevar a la indiferencia por parte del gobierno que se ve favorablemente impactado, sobre todo en materia fiscal, cuando se comparten nociones tan peligrosas como la mantener a los indígenas confinados en sus selvas, en antiguas usanzas que ponen en riesgo la vida de los miembros del grupo, e incluso, pudiendo llevar al exterminio de su comunidad. Contrariamente, es preciso aprovechar la afirmación hecha por la Corte, en la sentencia T-380 de 19937, acerca de las Comunidades Indígenas como "sujeto de derechos fundamentales", para exigir el traslado de políticas públicas con impactos favorables a su desarrollo, bajo el entendido de ser parte del aquí y del ahora, y de un mundo globalizado cada vez más alejado de los intereses nacionales, y qué decir de lo referido a lo local. Por su parte, los juristas nacionales deben ser los primeros convocados a la defensa de esta postura, bajo el entendido del principio de "Derecho Vivo" en contraposición con el concepto de "ancestralidad" y "tradición", evidenciando un incesante e indetenible proceso evolutivo al que es mejor pertenecer y aprovechar a mantenerse distante y rezagado.

En la Política Vernácula, Kymlicka (1996, p. 33) ha señalado como parte del debate filosófico sobre los derechos de las minorías que "la mayoría de los grupos etnoculturales en el seno de las democracias occidentales no quieren ser protegidos de las fuerzas de la modernidad que actúan en las sociedades liberales", esto con el fin de establecer la necesidad de unos mínimos vinculantes con el resto de la nación, lo que el autor denomina "cultura societal", para hacer referencia a la importancia que tiene "compartir" un mismo idioma nacional como parte esencial de la democracia. En este punto, Kymlicka muestra cómo los derechos de las minorías mantienen relación con otros y que, frente a temas como estos, las minorías deben

COLOMBIA. CORTE CONSTITUCIONAL. Sentencia T-380 de 1993. M.P. Eduardo Cifuentes Muñoz. 
elegir entre hacer posible su participación en el Estado a partir de unos mecanismos específicos de co-relación como el idioma, esencialmente, o permanecer voluntariamente aislados de los procesos en pos de la preservación de la cultura original, asumiendo un cierto grado de desventaja frente a las mayorías, pero, entendiendo que el acercamiento a la cultura mayoritaria forma parte de la vinculación a los proyectos y agendas que favorecen el desarrollo social y la preservación de la cultura (Blanco, 2008, p. 111).

En síntesis, y de acuerdo con el profesor Frank Semper, al Estado le preocupa la autonomía indígena desbordando el marco constitucional (Semper, 2006), pero debe ser una preocupación real de los colombianos el que las garantías consagradas por el Estado para la preservación de su más cercana identidad racial y cultural, supere los meros enunciados constitucionales y se vea favorablemente impactado con políticas efectivas, vigentes y de cobertura total, de lo contrario, adicional al acercamiento a la cultura mayoritaria a partir de la co-relación cultural, será el conflicto armado interno el que ponga fin a las comunidades indígenas nacionales de tanta significación para los colombianos, y esto, como es bien sabido, a causa de las constantes e innumerables formas de acoso y violación a los Derechos Humanos de que es y ha sido víctima este sector social.

\subsection{Elementos que afectan la Autonomía}

El censo oficial practicado por el DANE (Departamento Nacional de Estadísticas) a solicitud del Estado, en el año 2005, arrojó una cifra de 87 pueblos indígenas coincidente con los 102 pueblos que la ONIC (Organización Nacional Indígena de Colombia) ha detectado, para un total oficial de población de 1.378 .884 personas, pero con una alarmante cifra de 18 grupos indígenas en peligro de extinción ${ }^{8}$; sin embargo, para la Corte Constitucional son 35 los grupos indígenas que están en peligro de desaparecer a

8 Pueblos Indígenas en Colombia. El trabajo de ACNUR con pueblos indígenas. En: www.acnur.org causa del conflicto armado y el desplazamiento . $^{9}$ Las mismas cifras hablan de aproximadamente 70.000 desplazados internos correspondientes a comunidades indígenas exclusivamente, pero la ONIC afirma que puede tratarse de muchos más, quienes por razones como la lengua o las distancias no se les permiten realizar los registros requeridos para el Estado. Las causas del desplazamiento están en el reclutamiento forzado, la desaparición forzada, las masacres, las minas antipersonal, la violencia sexual, las ejecuciones extrajudiciales, las fumigaciones, los cultivos ilícitos, entre tantas otras razones propias de un Estado que afronta un agudo conflicto armado no internacional.

Durante años, las comunidades indígenas en Colombia han sido víctimas de múltiples vejaciones y maltratamientos, pero la condición más importante es su calidad de habitante en parte de las reservas naturales de mayor riqueza, fácilmente convertidos en el blanco del conflicto. Acerca del desplazamiento hay dos situaciones que deben tratarse: la primera está consignada en el art. 16 de la Convención $169^{10}$, numeral 5, "Deberá indemnizarse plenamente a las personas trasladadas o reubicadas por cualquier pérdida o daño que hayan sufrido como consecuencia de su desplazamiento" y numeral 3, "siempre que sea posible, estos pueblos deberán tener el derecho de regresar a sus tierras tradicionales en cuanto dejen de existir las causas que motivaron su traslado y reubicación". Con estos dos referentes se podría observar que existe una deuda del Estado para con los indígenas, dado la cantidad de quienes han debido salir huyendo de la guerra y abandonar sus territorios; pareciera en este caso no contar la palabra "ancestralidad", porque esos territorios abandonados son "territorios ancestrales" de las comunidades que allí habitaban; y de este punto se pasa inmediatamente al segundo, el desarraigo que trae como consecuencia el fin de la Jurisdicción Especial y conlleva a una presionada forma de contacto con un mundo

9 COLOMBIA. CORTE CONSTITUCIONAL. Autor 004 de 2009 y Auto 382 de 2010.

10 www.oit.org 
ajeno, agresivo y violento, al cual deben insertarse -generalmente- en calidad de indigentes, en este aspecto tampoco cuenta la amenazante "aculturación", que desprovee al indígena de un mundo original y lo obliga a refugiarse en una ciudad y en una sociedad desconocida y plenamente ajena a su mundo y a su interés.

\section{ACERCA DEL PRINCIPIO DE PLURALIDAD EN LO JURÍDICO}

En Colombia, la CP ha consagrado la existencia de una Jurisdicción Especial en materia de administración de justicia, la que es descrita en detalle en los artículos 116, 246 y 247, esta es: la Justicia Penal Militar, la Justicia Especial Indígena y los Jueces de Paz, en su orden; así la Rama judicial del Poder Público en Colombia está descrita en el art. 11 de la Ley 270. Este tipo de justicias está dentro de los marcos constitucionales, pese a su especialidad; en el caso de la Justicia Especial Indígena, la CP señaló que una Ley de coordinación regularía esta forma de justicia especial con relación a la justicia nacional, pero hasta la fecha el Congreso no ha expedido dicha Ley de coordinación por lo que el rol le ha correspondido a la Corte Constitucional como instancia autorizada y competente para señalar las aclaraciones más pertinentes al respecto.

Otra gran dificultad se presenta con la Justicia Especial Indígena relacionada con la formación especializada respecto de la educación superior en este campo, dado que no existen currículos académicos que preparen a los futuros operadores judiciales, jueces, legisladores, etc., en el conocimiento y tratamiento de la materia, siendo un asunto muy particular al interior de las comunidades con escasas contribuciones formales desde la academia.

La Convención 169 de la OIT, en su artículo $9^{\circ}$, ha dicho con relación a la Justicia Especial Indígena, que es preciso compatibilizarla con el sistema jurídico nacional y con los Derechos Humanos Internacionales, lo cual desvirtúa el carácter plenamente autónomo de sus funciones porque además de sujetarlo a la Constitución lo involucra en un plano más global que apunta a la protección y cumplimiento de los $\mathrm{DH}$. En este aspecto, se aprecia una contradicción entre lo que se ha denominado "usos y costumbres" y los arts. $7^{\circ}$ y 246 constitucional, particularmente en lo atinente con los métodos y los procedimientos aplicados en tratamientos de carácter penal.

Otro factor, esta vez de orden nacional, limitante de la autonomía en la Justicia Especial Indígena, está descrito en la sentencia T-048 de 2002 $y$ hace referencia al ejercicio y aplicabilidad por las autoridades indígenas de la justicia al interior de sus territorios, quienes forman parte de la Jurisdicción Especial, constituyéndose en una especie de fuero judicial para los indígenas que habitan en uno de los resguardos de la Jurisdicción; la limitación que se plantea se da con respecto a los métodos y procedimientos de la justicia nacional. El fuero no sólo hace referencia al hecho de cometer un acto contrario a la norma al interior de la comunidad, también está definido por el grado de contacto del sujeto involucrado en relación con la sociedad mayoritaria, un tanto para verificar si se trata o no de un caso de inimputabilidad cultural, donde la acción se cometió por desconocimiento, es decir, sin dolo.

Esta última condición que impone la justicia nacional en cuanto al fuero que concede la justicia especial indígena, retrocede la consideración hecha en líneas anteriores cuando se expresó la necesidad de compartir un lenguaje común, con los no indígenas miembros de su comunidad; aquí se vuelve a la pertinencia de "conservarlos" bajo un grado determinado de aislamiento que justifique el "desconocimiento" de los actos cometidos, o tal vez, el desconocimiento de los malos ejemplos y costumbres que la sociedad mayoritaria le pueda transmitir, sin antes haber puesto unos puntos de encuentro en el diálogo, que le indiquen lo que debe tomar y lo que no debe tomar de la realidad en la cual inevitablemente se halla incurso. Lo que protege el fuero indígena a través de la inimputabilidad cultural es el desconocimiento que provoca el aislamiento, terminando en ser una restricción 
que niega el "Derecho Vivo", y la posibilidad de un "acercamiento" cultural del cual puedan salir beneficiados no sancionados.

De acuerdo con Enrique Mora Ayala, en "El derecho ecuatoriano y el aporte indígena" 11 , la pertenencia de dos prácticas judiciales a un mismo sistema de ordenamiento nacional tiene como consecuencia la necesidad de establecer los puntos de coordinación dado que no se trata de un sistema paralelo sino de uno especializado del sistema de justicia nacional, lo cual es puesto de presente en el art. 246 constitucional cuando, en materia de autonomía, claramente es enmarcada dentro de los parámetros constitucionales que en ningún momento y por ninguna razón puede transgredir. En la Sentencia T-523 de 1997, la Corte advirtió acerca de unos posibles "conflictos de competencia" que se pudieran presentar entre la justicia especial indígena y la justicia ordinaria, en especial cuando son propiciados por los mismos actores indígenas, quienes al rechazar las decisiones de su justicia particular recurren a la justicia ordinaria tal como si se tratara de una instancia con la competencia de modificar la pena de quienes han sido condenados (Blanco, 2008, p. 110).

Volviendo al dilema que marca el tema de la "ancestralidad", respecto de la pertinencia de un "aislamiento" con relación al resto de habitantes del territorio, en el año 2003, el Senador Carlos Gaviria Díaz adelantó una discusión en el Congreso en torno al concepto de "culturas ancestrales" por traducir una forma de estancamiento de los indígenas en un mundo en permanente evolución y dinamismo; la propuesta de Gaviria Díaz resultó estructural para la declaración de inexequibilidad del art. $1^{\circ}$ de la Ley 89 de 1890 que clasificaba a los indígenas en "salvajes" y "civilizados", además de tratar a las comunidades como "incipientes sociedades". La inexequibilidad del artículo fue dictada mediante sentencia C-139 del 9 de abril de 1996, además, la Ley fue demandada porque otorgaba a los indígenas la mayoría de edad a los 21 años mientras para el resto de colombianos lo

11 www.uasb.edu.co hacía a los 18, guardándose una consideración de "minoría de edad" con efectos mentales (art. 40); los artículos invocados en la acción judicial fueron doce, de todos ellos el derecho a la igualdad fue el determinante.

De vuelta al art. $9^{\circ}$ de la Convención 169 que hace parte del Bloque de Constitucionalidad, y que establece la compatibilidad entre los métodos y procesos adoptados por la Justicia Especial Indígena y los Derechos Humanos Internacionales, nuevamente plantea discrepancias alrededor de los conceptos de "ancestralidad" y "tradicionalidad" al interior de los denominados "usos y costumbres", en lo que toca a la necesidad de ceñirse a unos "mínimos éticos" al momento de aplicar las disposiciones dictadas por los jueces indígenas, esto es, las restricciones que se imponen a las formas de castigar a quienes contravienen los pactos de convivencia en las comunidades. Para mayor claridad está el caso de los paeces quienes aplican como castigos más usuales el fuete, el trabajo forzado en las empresas comunitarias, las indemnizaciones a personas o familias de los afectados y la expulsión del territorio. La Corte Constitucional, en la sentencia T-523 de 1997 argumentó por qué el fuete y el destierro, entre los paeces, no constituyen tortura ni pena degradante. En el caso de fuete o flagelación con "perrero de arriar ganado", constituye un elemento purificador del individuo y simbólicamente representa la figura del "rayo", no es considerado tortura porque el daño corporal que produce es mínimo, y no es humillante porque su utilización es normal entre la comunidad.. En cuanto a la pena de destierro, ésta debe realizarse sin sobrepasar los límites de la J.E. porque de lo contrario sería causar un extrañamiento a algún lugar del territorio nacional, ocasionando la pérdida de los beneficios de la J.E.I. y esto sería una forma de expulsión que contraría tanto el Pacto Internacional de Derechos Políticos y Civiles, la Convención Americana sobre Derechos Humanos y el art. 38 de la CP.

En otros casos, el estricto seguimiento a los "usos y costumbres" y al apego a la "ancestralidad" ha causado peligrosos retrocesos en cuanto al 
derecho a la vida y a la salud de los miembros de las comunidades, la afectación provocada por algunas creencias e interpretaciones se sobrepone a los elementos de la ciencia y la tecnología, y por atender de lleno a estos saberes tradicionales han llegado, incluso, a la muerte de sus propios hermanos. El más reciente caso publicitado por los medios de comunicación ocurrió en Bogotá el 30 de agosto de 2011, cuando se registró la muerte de un bebé de dos meses de la comunidad Embera Katío, causada por los padres al negarle el suministro de un medicamento para tratar un caso de rinofaringitis, detectado por un médico del hospital San Cristóbal del barrio 20 de julio, cuatro días antes del deceso; la actitud de los padres se debió a que el medicamento contrariaba sus creencias.

Otro acontecimiento que causó conmoción nacional e internacional, ocurrido en agosto de 2008, estuvo relacionado con la hospitalización de dos jóvenes indígenas de la comunidad Embera ubicada en el departamento de Risaralda, a causa de una severa infección provocada por una práctica de ablación artesanal, la misma amputación de clítoris que practican algunos pueblos africanos y orientales. Naciones Unidas indicó que esta práctica constituía una forma de violencia física y síquica para las niñas sometidas a semejante tratamiento:

"La mutilación genital femenina es una violación de los derechos humanos, un hecho que los Emberá deben estudiar y analizar para evitar el dolor, los traumas y la muerte de sus niñas. Por eso para Naciones Unidas es imprescindible el diálogo con los Emberá y buscar con ellos una solución definitiva que ponga fin a esta práctica que viola los derechos de las niñas"12.

El Fondo de Población de las Naciones Unidas UNFPA, en asocio con el Instituto Colombiano de Bienestar Familiar ICBF, el Ministerio del Interior y

12 No más mutilación genital femenina en Colombia. En. Programa de radio Naciones Unidas Manos amigas. En: www.nacionesunidas.org.co de Justicia, el Ministerio de la Protección social, la Organización Internacional para las Migraciones, la Defensoría del Pueblo y la Procuraduría General, iniciaron un proyecto titulado "Embera Wera", que traduce de la lengua nativa "Mujer Embera", y cuyo fin era el acompañamiento a la mujer indígena del Departamento de Risaralda en el proceso, con una sensibilización que llevara a la cancelación de la ablación femenina, como parte de sus derechos.

El resultado de este trabajo fue publicitado por la Agencia EFE de noticias, el 23 de noviembre de 2010, bajo el titular "Indígenas prometen abandonar la ablación genital femenina", esta noticia contenía parte de lo anunciado por las autoridades Embera en la plaza principal de la ciudad de Pereira, luego de haber asistido a la película autobiográfica "Flor del desierto" (Desert Flower), que narra la historia de una modelo somalí que fue igualmente sometida a la práctica de la ablación. El cierre del acto no se dio sin que antes de ello se pronunciara la directora del proyecto "Embera wera" y anotara que en Colombia la Constitución abre la puerta a la diversidad cultural, pero luego entra en contradicción cuando se presentan situaciones tan particulares y culturales como éstas, que indudablemente afectan los derechos humanos de la población ${ }^{13}$.

En el segundo de los casos presentados es muy evidente la posición que se ha guardado en este artículo, aún cuando es claro que la problemática se aprecia tanto en uno como en otro. Cuando Naciones Unidas llama a un "diálogo" con los Emberas, y pone en marcha un proyecto, el "Embera wera", para sensibilizar a los indígenas de no continuar con las prácticas de ablación genital, y cuando finalmente la comunidad expresa su compromiso de poner fin a esta tradición, la práctica está otorgando la razón a la idea que aquí se ha manejado, acerca de la necesidad de entablar una comunicación cercana, directa y amable entre los indígenas y la sociedad

13 Indígenas prometen abandonar la ablación genital femenina. Agencia EFE, noviembre 23 de 2010. En: www.caracol.com.co 
mayoritaria, con el fin de mostrarles un mundo con otro tipo de posibilidades, a las cuales pueden acceder como parte de sus beneficios sociales en materia de políticas públicas, en lugar de mantenerlos alejados de una realidad que no les es ajena, entonces, es el momento oportuno para que la comunidad nacional e internacional, entre no a "escandalizar" sino a "contactar" un mundo con otro. Ahora bien, podría aducirse que tanto los padres de la bebé fallecida a causa de un mal tratamiento contra un cuadro de rinofaringitis, o los sujetos que practicaron la amputación del clítoris a las niñas Embera, lo hicieron bajo el estado de "inimputabilidad cultural" a efecto del desconocimiento de las consecuencias donde no existe un victimario pero si muchas víctimas. La reflexión conduce a repensar en si es posible mantener este concepto de "inimputable cultural" a una persona que continúa cometiendo un delito (para la sociedad no indígena) a falta de una efectiva comunicación, que antes de ser "aculturizante" sea una alternativa de vida, de la cual se puede y se debe o no aprender.

\section{CONCLUSIONES}

No cabe duda de que la tierra ha sido el elemento más importante sobre el cual descansa el desarrollo de las comunidades indígenas en Colombia, de ella depende la preservación de la cultura y el ejercicio de su mundo, a partir de su propia concepción.

Igualmente, es insuperable la importancia que reviste la Jurisdicción Especial Indígena, como logro alcanzado por los indígenas colombianos a lo largo de su lucha social, desde la Constitución de 1821, cuando se empezó a plantear la necesidad de concederles derechos individuales, que pusieron en riesgo la propiedad colectividad y con ello, la estabilidad social y cultural de las comunidades. Pero debe manejarse con sumo cuidado lo que al interior de estos demarcados territorios puede y debe compartirse. Si bien el Estado les ha concedido un grado de autonomía, obviamente enmarcado dentro de los límites constitucionales, esta puede tener varias implicaciones:
1. La primera, tiene que ver con un tipo de autonomía restringida en razón al debate provocado por la idea de "preservar lo original", pero a la vez inserto en la innegable globalización, a la cual no sólo se pertenece por modelo mundial, sino que se corresponde jurídicamente a efectos legales como el Bloque de Constitucionalidad. Sin duda, estos dos ingredientes, provocan desconcierto en los términos de operatividad y funcionalidad de lo local, de lo constitucional y nacionalmente protegido.

2. La segunda, guarda relación con el cumplimiento estricto de respeto y conservación a las prácticas culturales, esta rigurosa condición podría conllevar -para algunos- a que la presencia social del Estado se tomara como una intromisión un tanto amenazante, al grado de ser percibida como atentatoria a lo autóctono, a lo original; es preciso considerar que una posición al margen por parte del Estado sería socialmente inconveniente en razón a la necesidad de fortalecer políticas públicas en beneficio de la salud y la educación, por ejemplo, en esta parte del problema, convocar a un diálogo compartido es apenas necesario, es prudentemente benéfico.

3. La tercera, equivale al sentido que puede cobrar la palabra "ancestralidad", que si bien es un argumento que marca el fuero en materia judicial, igualmente contradice los códigos que a diario manifiestan la indetenible marcha del mundo y de sus actores; como se ha apreciado en el texto, las gravísimas afectaciones que se han presentado al interior de las comunidades, no puede ni deben explicarse desde la "ancestralidad", dado que las afectaciones de este orden no son precisamente las llamadas a conservarse como parte de la identidad.

Lo que el texto ha querido mostrar al lector es que la Jurisdicción Especial por apropiada $e$ importante, está en riesgo, bien por parte de los actores del conflicto que es la parte más álgida y aguda de todo el proceso, bien por parte del 
Estado que no ha tenido tiempo, ni métodos, ni herramientas, ni protagonistas, para establecer la coordinación formal y legal entre esa puerta abierta que la CP dejó a la autonomía y los marcos constitucionales a los cuales fue igualmente restringida; $\mathrm{O}$, a consecuencia de las mismas comunidades que a falta de un proyecto nacional "vinculante", y por absoluto desconocimiento, permanecen alejadas de los beneficios que la sociedad, el Estado y la ciencia pueden y deben aportarles.

La defensa de las comunidades indígenas nacionales, de su cultura, y de su autonomía, debe ser una declaración urgente que se emprenda desde la academia hasta el Estado, pero reviste una primaria necesidad el hecho de encontrar un punto equidistante entre uno y otro proyecto, el de la sociedad mayoritaria y el de las comunidades indígenas, para evitar imprecisiones, incoordinaciones, $y$ ante todo, rechazo a unas formas propias de vida; ellas deben ser respetadas pero a la vez, deben respetarse desde su particular interior, dada la necesidad de conservación y de proyección, algo así como un punto medio pero que se niegue a amenazar desde la absurda asimilación.

\section{BIBLIOGRAFÍA}

AAVV. (2000). Algunos rasgos de la estadística aborigen. Geografía humana de Colombia. Tomo IV. Vol. II. Bogotá: ICCH, 2000.

BLANCO BLANCO, Jacqueline. (2008). La Jurisdicción Indígena, más allá del mandato constitucional. Bogotá, Universidad Libre.

CASTRO GOMEZ, Santiago. (2007). Pensamiento colombiano del siglo XX. Bogotá: Universidad Javeriana.

COLOMBIA. CORTE CONSTITUCIONAL. Sentencia T-625 de 1998. En: www.corteconstitucional.gov.co

COLOMBIA. CORTE CONSTITUCIONAL. Sentencia T-380 de 1993. M.P. Eduardo Cifuentes Muñoz.
COLOMBIA. CORTE CONSTITUCIONAL. Autor 004 de 2009 y Auto 382 de 2010.

COLOMBIA. CONSTITUCIÓN POLÍTICA, 1991. En: www.cervantesvirtual.com

CONSTITUCIÓN DE CUNDINAMARCA DE 1811. En: www.cervantesvirtual.com

HERREÑO HERNANDEZ, Ángel Libardo. (2004). Evolución política y legal del concepto de territorio ancestral indígena en Colombia. En: El otro derecho No. 31-32. Bogotá: ILSA, agosto de 2004.

GALINDO CARDONA, Yamid. (s.f.) Tierra y piel en el ser indio de Miguel Lame Chantre. En: www.historiayespacio.com

GRIJALVA, Agustín. (s.f.) ¿Qué son los Derechos Colectivos? Ecuador: Universidad Andina Simón Bolívar. En: www.uasb.edu.ec

IBERO, Mario. (1924). "Una entrevista en el centro del poder: el pensamiento del hombre es ciertos trances es un secreto que debe guardar muy bien el corazón". El Espectador, julio 12 de 1924. En: GALINDO CARDONA, Yamid. Tierra y piel en el ser indio de Miguel Lame Chantre. En: www.historiayespacio.com

No más mutilación genital femenina en Colombia. En. Programa de radio Naciones Unidas Manos amigas. En: www.nacionesunidas.org.co

JIMENO SANTOYO, Myriam. (1992). Los indígenas colombianos, hoy. Su situación real, problemas y alternativas. En: Revista Credencial Historia No. 33. Bogotá, Septiembre.

KYMLICKA, Will. (2003). La Política Vernácula. Buenos Aires: Paidós.

Ley de 20 de mayo de 1828. Artículo 1. En: BUSHNELL, David. Colombia una Nación a pesar de sí misma. Bogotá: Editorial Planeta, 1994.

Ley 089 del 25 de noviembre de 1890. En: www. alcaldiadebogota.gov.co

MANUEL QUINTIN LAME. Tomada de la Gran Enciclopedia de Colombia del Circulo 
de Lectores. Tomo Biografías. En: www.banrepcultural.org.

MAYORGA GARCIA, Fernando. (1994). Los resguardos indígenas y el petróleo, orígenes y perspectivas del oro negro en Colombia. En: Revista Credencial Historia No. 49. Bogotá, Enero. En:www.lablaavirtual.com.co

MEJIA VILLA, David. (s.f.) Leyes republicanas de indios. Aportación de la Independencia a la Legislación Civil en pro de los indígenas. Antecedentes y período 1821 a 1843. Universidad de La Sabana. Facultad de Derecho. En: www. dialnet.unirioja.es

MORALES BENITEZ, Otto. (s.f) Revolución y Caudillos. Capítulo VIII. En: www.banrepcultural.org

Naciones Unidas - Centro de Información. En: www.cinu.org.mx

PINEDA CAMACHO, Roberto. (s.f.) Estado y pueblos indígenas en el siglo XX. La política indigenista entre 1886 y 1991. En: Biblioteca Virtual del Banco de la República www.banrepcultural.org.
Pueblos Indígenas en Colombia. El trabajo de ACNUR con pueblos indígenas. En: www. acnur.org

RIVERA, José Eustasio. (2005). La Vorágine. Edición crítica Luis Carlos Herrera Molina S.J. Bogotá: Universidad Javeriana.

SANDERS, James. (2007). Pertenecer a la gran familia granadina. Lucha partidista y construcción de la identidad indígena y política en el Cauca, Colombia, 1849-1890. En: Revista de Estudios sociales No. 26. Bogotá, Abril.

SEMPER, Frank. (2006). Los Derechos de los Pueblos Indígenas de Colombia en la Jurisprudencia de la Corte Constitucional. En: Anuario de Derecho Constitucional Latinoamericano. Biblioteca Jurídica virtual del Instituto de Investigaciones Jurídicas de la UNAM. www.jurídicas.unam.mx

SINISTERRA RODRIGUEZ, Mónica María. (s.f.). Dependencia de la Historia en la determinación del capital social, herencia colonial y cambio institucional: el caso caucano. En: www.revistas. unal.edu.co 